\title{
Rare early prosthesis obstruction after mitral valve replacement: a case report and literature review
}

\author{
Jun Shi, Zhi-xuan Bai, Jia Hu, Ben-gui Zhang and Ying-qiang Guo*
}

\begin{abstract}
As a dreadful complication after the mechanical heart valve replacement, prosthetic valve obstruction caused by pannus formation occurs increasingly with time. The authors here present a case of 42 -year-old woman who was urgently admitted to hospital with acute heart failure symptoms due to the mechanical mitral valve failure only 3 months after surgery. Transthoracic and transesophageal echocardiography demonstrated that the bileaflet of the mitral prosthesis were completely immobilized with only a small transvalvular jet remained. During the reoperation, the reason of the prosthetic valve obstruction was attributed to the noncircular pannus ingrowth extending from the atrioventricular side. For a better understanding of the prosthetic valve dysfunction caused by pannus formation, the authors then compile a literature review to briefly discuss the status quo of the clinical characteristics of this uncommon complication.
\end{abstract}

\section{Background}

The evolving design and biomaterials of the mechanical heart valves have greatly advanced their in vivo hemodynamic features and durability over decades [1]. However, the anticipated performances of the mechanical prostheses are still compromised by the occurrence of various complications, among which pannus-induced prosthetic valve dysfunction (PVD) is relatively uncommon but sometimes is the most serious one [2,3]. In particular, patients with prosthetic valve obstruction (PVO) due to pannus ingrowth may rapidly develop hemodynamic deterioration and crash into a life-threatening condition. According to recent studies [2,4-7], the prevalence of pannus formation in aortic or mitral position is controversial. However, pannus is undoubtedly of later clinical onset than the thrombosis, which is mostly responsible for the early PVD. Moreover, the duration from time of prostheses implantation to pannus-induced PVD is widely variable and has been reported to be at least 6 months to 12 months, during which an ingrowth of periannular tissue would gradually immobilize the moving element of the prostheses [6-8]. Here we present a rare case

\footnotetext{
* Correspondence: drguoyq@hotmail.com

Department of Cardiovascular Surgery, West China Hospital, Sichuan University, Cheng Du, People's Republic of China
}

of PVO in the mitral position caused by early pannus formation only 3 months after surgery.

\section{Case presentation}

A 42-year-old woman was admitted to our intensive cardiac care unit with symptoms of acute left heart failure. Three months prior to admission, she underwent the implantation of a mechanical bileaflet mitral valve (25 mm SJM Master; St. Paul, MN, USA) due to severe rheumatic valve stenosis. No native valve- or chordalsparing procedures were performed during the replacement. The postoperative course went smoothly and transthoracic echocardiography (TTE) showed proper functioning of the prosthesis. The patient then followed adequate anticoagulation treatment with wafarin and the international normalized ratio maintained above 2.0. No episode of atrial fibrillation and other risk factors for thrombus formation were identified. One week before this admission, she had noticed a progressive physical deterioration. After the treatment at local hospital, the patient showed no signs of recovery and finally presented with severe shortness of breath and coughing up pink, foamy mucus on the arrival of our hospital.

On admission, the patient was conscious but presented with marked respiratory distress. Initial vital signs showed blood pressure $80 / 40 \mathrm{mmHg}$, sinus rhythm, a regular pulse of 140 beats/min and a respiratory rate of 40 breaths/min. Auscultation of the chest revealed 


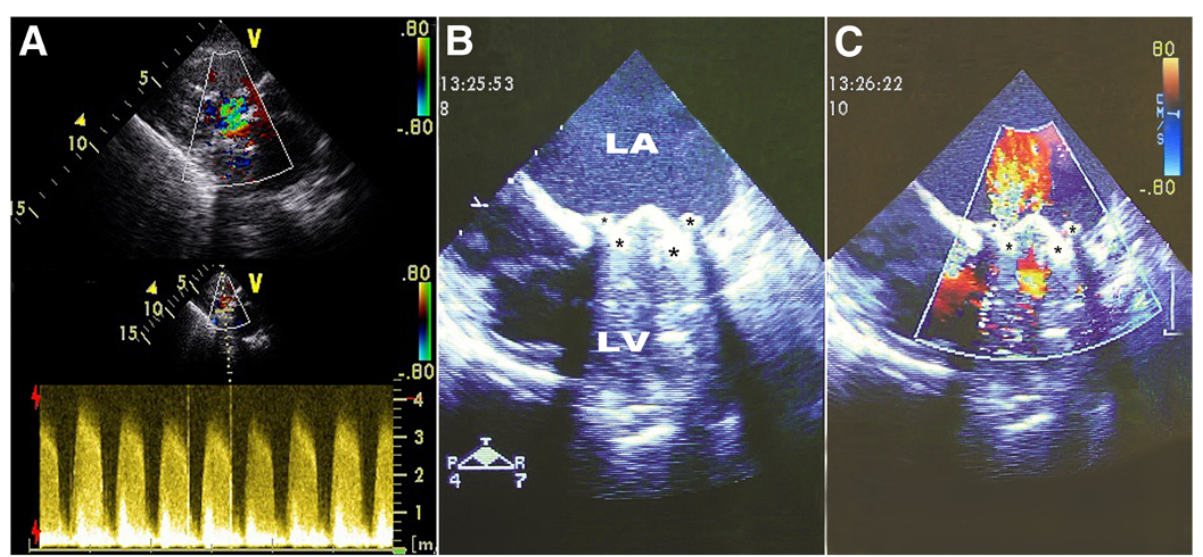

Figure 1 Echocardiography of mitral prosthesis: A) Transthoracic echo reveals immobilization of the mechanical bileaflet with accelerated velocity of transvalvular blood flow; B) and C) Intraoperative transesophageal echo demonstrated prosthetic valve obstruction due to pannus formation (asterisks) on atrioventricular side. LA indicates left atrium; LV indicates left ventricle.

diffuse rhonchi and expiratory wheezes without any distinct heart murmurs. No signs of jugular venous distention and extremities edema were observed. The patient was intubated due to the deteriorated respiratory status. After intubation, bedside TTE demonstrated that the prosthetic bileaflet was immobilized and only a small transvalvular jet was observed. However, no paravalvular leakage, and vegetations or periannular abscesses that indicating endocarditis were identified (Figure 1A).

In view of the patient's unstable hemodynamic conditions and echocardiographic findings, an emergent surgical intervention was performed. Intraoperative transesophageal echocardiography (TEE) demonstrated the immobilization of the prosthetic leaflets, which might be attributed to the acoustic shadowing around the valve ring (Figure $1 \mathrm{~B}$ and Figure $1 \mathrm{C}$ ). During surgical inspection, a noncircular fibrotic tissue ingrowth from the atrioventricular side was detected. The invaded pannus strictly adhered to the valve pivots and arrested both prosthetic leaflets (Figure 2). The failed prosthesis was explanted and a new $27 \mathrm{~mm}$ SJM Master mechanical valve was implanted. The postoperative course was regular and in-hospital TTE showed normal functioning of the newly implanted mitral prosthesis. The patient had an uneventful recovery and was discharged home at two weeks after surgery.

On microscopic examination (Figure 3), the resected pannus tissue was found to be mainly constituted with infiltrated leukocytes (neutrophils, macrophages, lymphocytes and plasma cells), pleomorphic spindle cells such as myofibroblasts, and interspersed capillary vessels.

\section{Discussion}

As an exuberant healing process in response to the implanted prosthesis, pannus formation occurs increasingly with time. Compared with valvular thrombosis, pannus is less frequently found to be an etiologic factor that contributes to the early PVD [2-8]. According to multiple clinical observations (Table 1), the duration

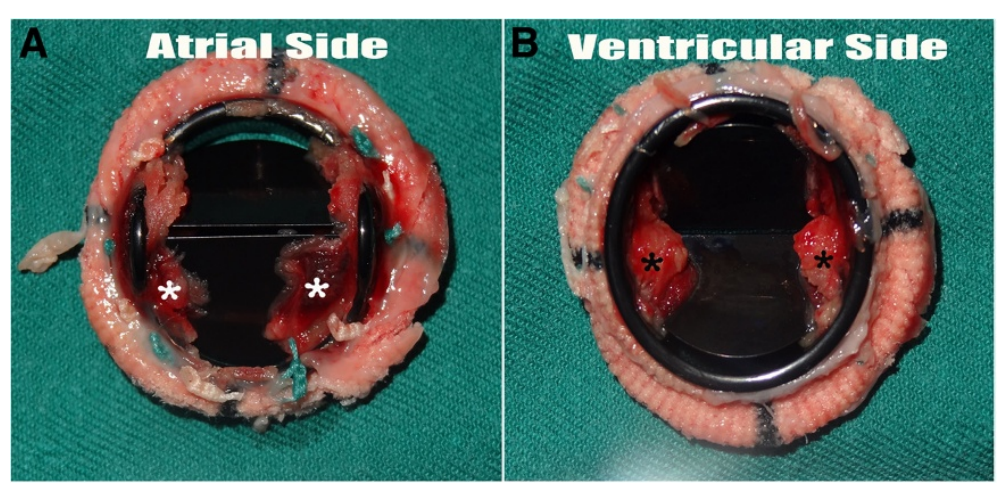

Figure 2 A macroscopic view of explanted St. Jude prosthetic valve with pannus ingrowth (asterisks): A) Atrial aspect; B) Ventricular aspect. 


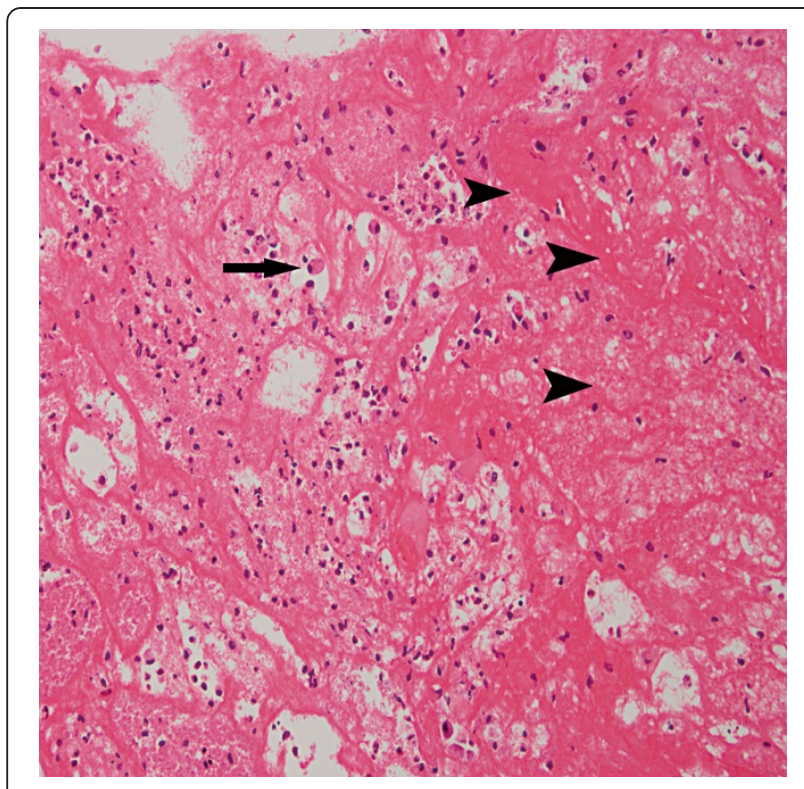

Figure 3 Histologic section shows that the specimen largely consist of infiltrated leukocytes (arrow) and pleomorphic spindle cells such as myofibroblasts (arrowheads), as well as interspersed capillary vessels. Magnification $\times 200$.

from the time of prostheses implantation to pannusinduced PVD varies widely and has been reported to be 1.8 years to 23 years after surgery [4-7,9,10], and a shorter time interval (6 months) has been described in patient with the prosthetic aortic valve [8]. However, in this case, the time interval from the initial replacement to PVO caused by pannus ingrowth was extraordinarily short. To our best knowledge, there were no reports of pannus-induced PVO within one year after mitral valve replacement [11].

The cause of the pannus-related PVD and PVO is generally considered as a chronic foreign body reaction to the prosthetic biomaterials. It is likely that an individual patient's inherent propensity with coexisting risk factors triggers and accelerates the progression of pannus formation. These associated factors can be summarized as follows: 1) Clinical characteristics of the patients: female, concomitant endocarditis and pregnancy, the history of rheumatic fever and valvular thrombosis, atrial fibrillation, low-output conditions, small valve annulus and inadequate anticoagulation [2,5-9] Design and biomaterials of the prostheses: tilting disc valves and caged-disk/ball valves due to low transvalvular flow $[7,11,14]$, the protruding design of the pivot guard systems in the SJM valves $[3,15]$ Surgical techniques: preservation of the native valve or subvalvular chordae [12,13], implantation of the prostheses with smaller size [9], the presence of periannular endothelial irregularities after implantation $[2,4,7]$. Taken together, as presented in our case, the history of severe rheumatic disease, small mitral annulus and implanted SJM prosthesis in this female patient may have contributed to the acute formation of the pannus.

The underlying mechanism of the pannus formation was supposed to be the significant proliferation and deposition of myofibroblasts, phagocytes and extracellular matrix, which are mediated by increased expression of transforming growth factor type beta-1 (TGF- $\beta 1$ ) in perivalvular tissue and circulating blood $[5,16]$. Moreover, some studies have suggested that the persistent release of fibroblast growth factor-2 (FGF-2) from the injured periannular tissue may also contribute to this chronic healing process [17]. Therefore, echo to these important observations, a promising therapeutic strategy to prevent pannus formation in high risk patients might be achieved by suppressing the proliferative responses in periannular tissues with the drug-coated prostheses.

The obstruction of prosthetic valves is largely caused by pannus, thrombus or both, so it is of great therapeutic implications to make differential diagnosis on

Table 1 Studies of mechanical prosthetic valves obstruction due to pannus formation

\begin{tabular}{|c|c|c|c|c|}
\hline Authors, years, [Ref.] & Type of studies & Position of Valves & Incidence \& Time Interval & Risk Factors \\
\hline Vitale et al. , 1997, [4] & Case series $(n=1878)$ & Mitral valves & $3.5 \%$, Mean $\geq 4$ years & Female, Tilting-disc valves, Bileaflet valves \\
\hline Barbetseas et al. , 1998, [6] & Case series $(n=23)$ & Mitral \&Aortic valves & $\begin{array}{l}\text { More common in aortic } \\
\text { position, } 178 \pm 52 \text { months }\end{array}$ & Not indicated \\
\hline Rizzoli et al. , 1999, [7] & Case series $(n=2680)$ & $\begin{array}{l}\text { Mitral \&Aortic } \\
\text { \&Tricuspid valves }\end{array}$ & $\begin{array}{l}0.24 \% / \text { patient/year, } \\
\text { Median = } 13 \text { years }\end{array}$ & Tilting-disc valves, Caged-disk/ball valves \\
\hline Teshima et al. , 2003, [5] & Case series $(n=615)$ & Aortic valves & $1.95 \%$, Mean $=83 \pm 52$ months & Inadequate anticoagulation, SJM valves \\
\hline Sakamoto et al. , 2006, [9] & Case series $(n=390)$ & Aortic valves & $1.8 \%$, Mean $=10 \pm 7.9$ years & Small prostheses size Turbulent Flow \\
\hline Kondruweit et al. 2008, [8] & A case report & Aortic valve & 6 months & Small prosthesis size, Rheumatic fever \\
\hline Mullenix et al. , 2008, [3] & A case report & Aortic valve & 15 years & Female, A tilting-disc valve \\
\hline Hurwitz et al. , 2009, [2] & A case report & Aortic valve & 8 years & Female, Endocarditis \\
\hline Khan et al. , 2009, [12] & A case report & Mitral valve & 7 years & Female, Subvalvular chordae preservation \\
\hline Matsuyama et al. 2011, [11] & A case report & Mitral valve & 27 months & Inadequate anticoagulation, female \\
\hline Park et al. , 2011, [13] & A case report & Mitral valve & 9 years & Female, Subvalvular chordae preservation \\
\hline
\end{tabular}


them. Because reopen heart surgery, either repeated valve replacement or resection of the ingrowth tissue [13], is the only option for managing the pannusinduced PVO, while thrombolytic therapy can serve as an alternative treatment in selected patients with thrombosed prostheses $[18,19]$. As reported in several echocardiographic studies, pannus in situ presents with a higher ultrasound-intensity ratio $(>0.7)[6]$ and is usually found to be a fixed lesion that attaches to the prosthetic ring [2]. Conversely, the thrombotic mass demonstrated in echo is mobile and is generally attaching to the valve occluder $[1,2,20]$. Although thrombolysis may be preferred for its less invasiveness in certain group of patients, surgical intervention, as for this case, should be unhesitatingly performed once the patients show any signs of hemodynamic instability.

\section{Conclusions}

With adequate anticoagulation and no preservation of subvalvular tissue in the first-time mitral valve replacement, the pannus-induced obstruction of an SJM bileaflet mechanical valve within such a short time interval was very uncommon. This rare case has added to a growing body of literatures describing the various clinical features of the pannus-related PVO. Further explorations on etiologic-specified prevention, and efficient treatment for this complication are required.

\section{Consent}

Written informed consent was obtained from the patient for publication of this case presentation and accompanying images. A copy of the written consent is available for review by the Editor-in-chief of this journal.

\section{Competing interests}

The authors declare that they have no competing interests.

\section{Authors' contributions}

All authors contributed equally to the manuscript and all authors read and approved the final manuscript.

Received: 9 December 2011 Accepted: 19 May 2012

Published: 2 July 2012

\section{References}

1. Aslam AK, Aslam AF, Vasavada BC, Khan IA: Prosthetic heart valves: types and echocardiographic evaluation. Int J Cardiol 2007, 122:99-110.

2. Hurwitz SE, Waxman D, Hecht S: Acute failure of a St. Jude's prosthetic aortic valve: large pannus formation masked by a small thrombus. J Am Soc Echocardiogr 2009, 22(1086):e1-e3.

3. Mullenix PS, Parsa CJ, Mackensen GB, Jollis JG, Harrison JK, Hughes GC: Pannus-related prosthetic valve dysfunction and life-threatening aortic regurgitation. J Heart Valve Dis 2008, 17:666-669.

4. Vitale N, Renzulli A, Agozzino L, et al: Obstruction of mechanical mitral prostheses: analysis of pathologic findings. Ann Thorac Surg 1997, 63:1101-1106.

5. Teshima H, Hayashida N, Yano H, et al: Obstruction of St Jude Medical valves in the aortic position: histology and immunohistochemistry of pannus. J Thorac Cardiovasc Surg 2003, 126:401-407.

6. Barbetseas J, Nagueh SF, Pitsavos C, Toutouzas PK, Quiñones MA, Zoghbi WA: Differentiating thrombus from pannus formation in obstructed mechanical prosthetic valves: an evaluation of clinical, transthoracic and transesophageal echocardiographic parameters. J Am Coll Cardiol 1998, 32:1410-1417.

7. Rizzoli G, Guglielmi C, Toscano G, et al: Reoperations for acute prosthetic thrombosis and pannus: an assessment of rates, relationship and risk. Eur J Cardiothorac Surg 1999, 16:74-80.

8. Kondruweit M, Flachskampf FA, Weyand M, Schmidt J, Achenbach S, Strecker T: Early failure of a mechanical bileaflet aortic valve prosthesis due to pannus: A rare complication. J Thorac Cardiovasc Surg 2008, 136:213-214.

9. Sakamoto $\mathrm{Y}$, Hashimoto K, Okuyama H, Ishii S, Shingo T, Kagawa H: Prevalence of pannus formation after aortic valve replacement: clinical aspects and surgical management. J Artif Organs 2006, 9:199-202.

10. Sugiura T, Koide M, Kunii Y, Umehara N: Pannus formation on St. Jude Medical prosthetic aortic valve 23 years after initial operation. Eur J Cardiothorac Surg 2008, 33:926.

11. Matsuyama K, Nakayama T, Hagiwara H: St. Jude prosthetic valve obstruction in the mitral position. Gen Thorac Cardiovasc Surg 2011, 59:350-353.

12. Khan NA, Butany J, Leong SW, Rao V, Cusimano RJ, Ross HJ: Mitral valvesparing procedures and prosthetic heart valve failure: a case report. Can J Cardiol 2009, 25:e86-e88.

13. Park B, Park PW, Park CK: Transaortic chordae and pannus removal without redo mitral valve replacement in prosthetic mitral valve malfunction. Eur J Cardiothorac Surg 2011, 39:1057-1058.

14. Durrleman N, Pellerin M, Bouchard D, Hebert $Y$, Cartier R, Perrault LP, et al: Prosthetic valve thrombosis: twenty-year experience at the Montreal Heart Institute. J Thorac Cardiovasc Surg 2004, 127:1388-1392.

15. Aoyagi S, Nishimi M, Tayama E, Fukunaga S, Hayashida N, Akashi H, et al: Obstruction of St Jude medical valves in the aortic position: a consideration for pathogenic mechanism of prosthetic valve obstruction. Cardiovasc Surg 2002, 10:339-344.

16. Teshima H, Fukunaga S, Takaseya T, Tomoeda H, Akashi H, Aoyagi S: Obstruction of St. Jude medical valves in the aortic position: plasma transforming growth factor type beta 1 in patients with pannus overgrowth. Artif Organs 2010, 34:210-215.

17. Ozeren M, Demirpence O, Han U, Dogan OV, Yucel E, Onal B: Effect of fibroblast growth factor-2 on pannus formation in replacement prosthetic heart valves. J Heart Valve Dis 2004, 13:676-680.

18. Nagy A, Dénes M, Lengyel M: Predictors of the outcome of thrombolytic therapy in prosthetic mitral valve thrombosis: a study of 62 events. $J$ Heart Valve Dis 2009, 18:268-275.

19. Shapira Y, Herz I, Vaturi M, Porter A, Adler Y, Birnbaum Y, et al: Thrombolysis is an effective and safe therapy in stuck bileaflet mitral valves in the absence of high-risk thrombi. J Am Coll Cardiol 2000, 35:1874-1880.

20. Lin S, Tiong I, Asher C, Murphy M, Thomas J, Griffin B: Prediction of thrombus-related mechanical prosthetic valve dysfunction using transesophageal echocardiography. Am J Cardiol 2000, 86:1097-101.

doi:10.1186/1749-8090-7-64

Cite this article as: Shi et al:: Rare early prosthesis obstruction after mitral valve replacement: a case report and literature review. Journal of Cardiothoracic Surgery 2012 7:64.

\section{Submit your next manuscript to BioMed Central and take full advantage of:}

- Convenient online submission

- Thorough peer review

- No space constraints or color figure charges

- Immediate publication on acceptance

- Inclusion in PubMed, CAS, Scopus and Google Scholar

- Research which is freely available for redistribution 